\title{
Installation or Conceptual Art Project with the Ceramics Phenomenon, but How and when?
}

\author{
Em. Prof. Güngör Güner
}

\section{Abstract}

With its formation, going back to thousands of years ago, ceramic is a material fact that the human beings obtain from earth for their emergency needs at first and by time for their different rituals and artistic requirements. Whether it is primitive or developed, ceramic formation requires energy and technology! And once ceramic is obtained, it resists time for thousands of years! Therefore, we have to be very selective when making ceramics! As ceramic artists, we always feel the breath of the tradition of thousands of years on our necks even if we want or not. Contemporary art trends show up one after another and disappear after a while. Meanwhile, "Is ceramic an art or a craft?" discussions are brought to agenda. Ceramic artists with a contemporary art education background may tend to keep up with the contemporary art trends because of the pressure caused by these discussions and the dominance of tradition. Among these art movements, Concept Art and Installation under its context still maintain their currency as the most long-lasting one in recent years. Concept is a most important part of the Conceptual Art Project! All materials or finished products that are created or will be created can be an expression tool for the artists. There is no limit here. However, knowing ceramic fact well can provide the ceramic artist with a chance to differentiate. For this reason, I believe that the ceramic artist's concern should be creating ideas that underline being different in the context of ceramic. Using ceramics will be more meaningful if the ceramic object used in the artwork can not be replaced by another object and if the concept changes when the ceramic object is replaced... Ceramic object should challenge as follows: "This concept can be expressed only if I am used here! "..... Forcing ceramic artist to be more creative will prevent the artist from imitation of an ordinary concept art or installation and will add variety to concept art by creating remarkable difference. Surely, this requires a more powerful mind exercise. However, this is the only way ceramic and ceramic artist can accomplish their mission and underline the difference.

Keywords: Installation, Conceptual Art, Project, Ceramics, Phenomenon 


\section{Introduction}

We, ceramists have countless tools and devices unique of our own those can differ from the other artists. For example; we have our potter's wheel and our wet clay which is born by clay and water meeting that of which every kind of shape can be formed out of it.

According to definition of German philosopher Martin Heidegger, because of these opportunities, "Ceramist is the person who shapes the space!"

Courses seriously started in Turkey by the end of 50's with State Senior High School of Applied Fine Arts and State Fine Arts Academy. Whereas by the beginning of 80's, as for the education institutions which were taken under the shelter of universities' umbrella and of which their numbers increased, university bachelor and post graduate education and adequacy in art programs and international communication opportunities which can be easily provided when compared to old are concerned, countless researches could have been done; unknown techniques and districts on the subject of ceramics almost left none. This means ceramist's self-expression tools with his work of art became rich.

1. For example, thirty years ago words like Raku, Sagar, Terra-Sigilata, Salt Glossed or Ash Glossed Firing, Paper Ceramics, Ceramics with Silica, Sieve Print, Laser Print, and Photocopy Transfer could be learn theoretical in technology courses but no applications were subject to word! In the parallel of all these stages, development of industry of ceramics and its selling of raw material or auxiliary ready tools and devices to small workshops and artistic studies provide an undeniable contribution.

Some Suggested Working Methods to Trigger to Became Creativity I used to give homework at the freshmen and sophomore classes during my teacher ship process at the Department of Ceramics of Marmara University Fine Arts Faculty in the content of Introduction to Ceramics' Art Education as such: "Do two researches as being upon abstract and concrete with the elements which were turned on the wheel." I want to share with you one, two concepts those I have observed that can trigger palette richness of the ceramist of which has been obtained or proved as a result of this and similar exercise methods, thus our originality.

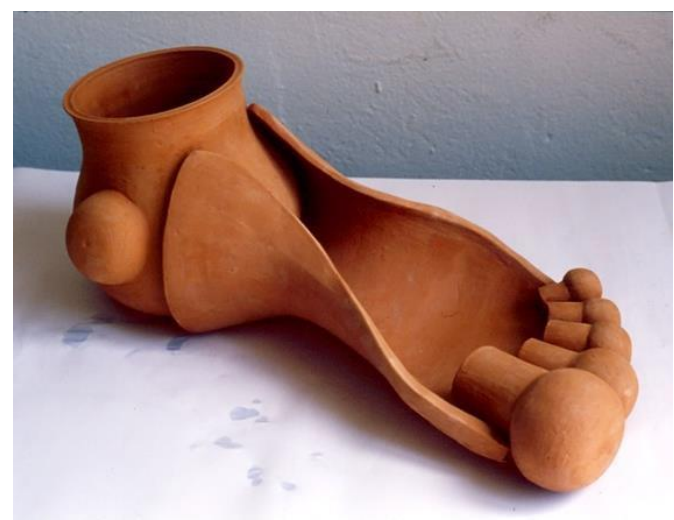

Picture 1.

A foot sculpture that only a ceramist can realize by using ceramics tools and devices! Here, ceramics concept has not been missed, contrary to that, potter wheel has been used of which jug has been made also with the jug mud, a wonderful work of art which makes feel you that it is challengingly proud with it instead of denying its origin and tradition. The most original and challenging foot sculpture that I have ever seen until today. (artist: Sibel Alparslan my student from Marmara University of Fine Arts Faculty) 


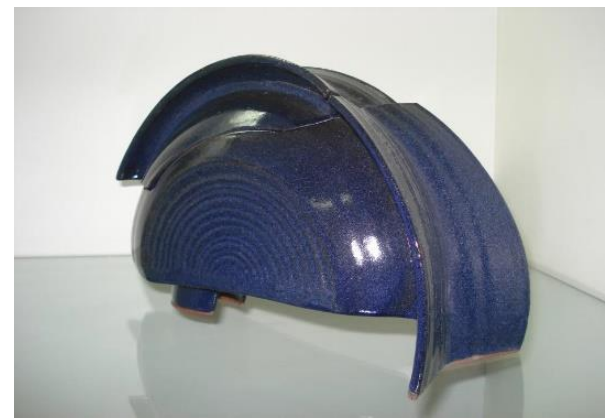

Picture 2.

A container sculpture realized by elements turned on potter's wheel In the context of homework above. (artist: Sule Dönmez, a student of mine from Marmara University Fine Arts Faculty)

Another homework that I have given to students in the context of Introduction to Ceramics Art Education was: "Realize a form preferably as it is going to be space internally upon and later deform it; but in the process of this deforming, main form and your method of deforming must be readable.

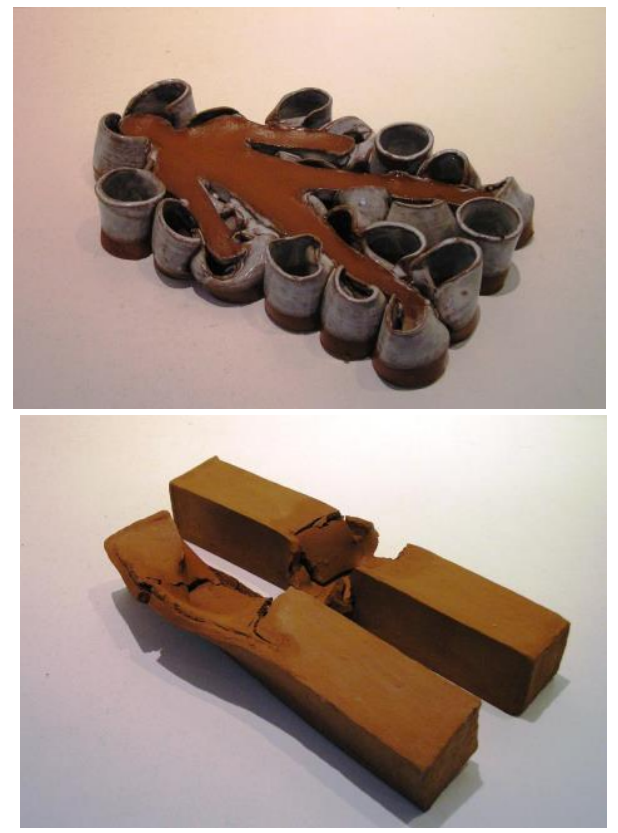

Picture 3.

Cylinders which have been turned on the potter's wheel, a shape change has been provided by mounting over the figure on them while they were wet. By which another material can such a fresh and organic deformation be provided?

(artist: Uğur Örsöz, a student of mine from Marmara University Fine Arts Faculty)

\section{Picture 4.}

A breach event realized by utilizing of the fragility of the clay after it is dried or fired as it is shaped. This is a very extremely unique privilege that can only be on ceramist' palette.

(artist: Duygu... a student of mine from Marmara University of Fine Arts Faculty 

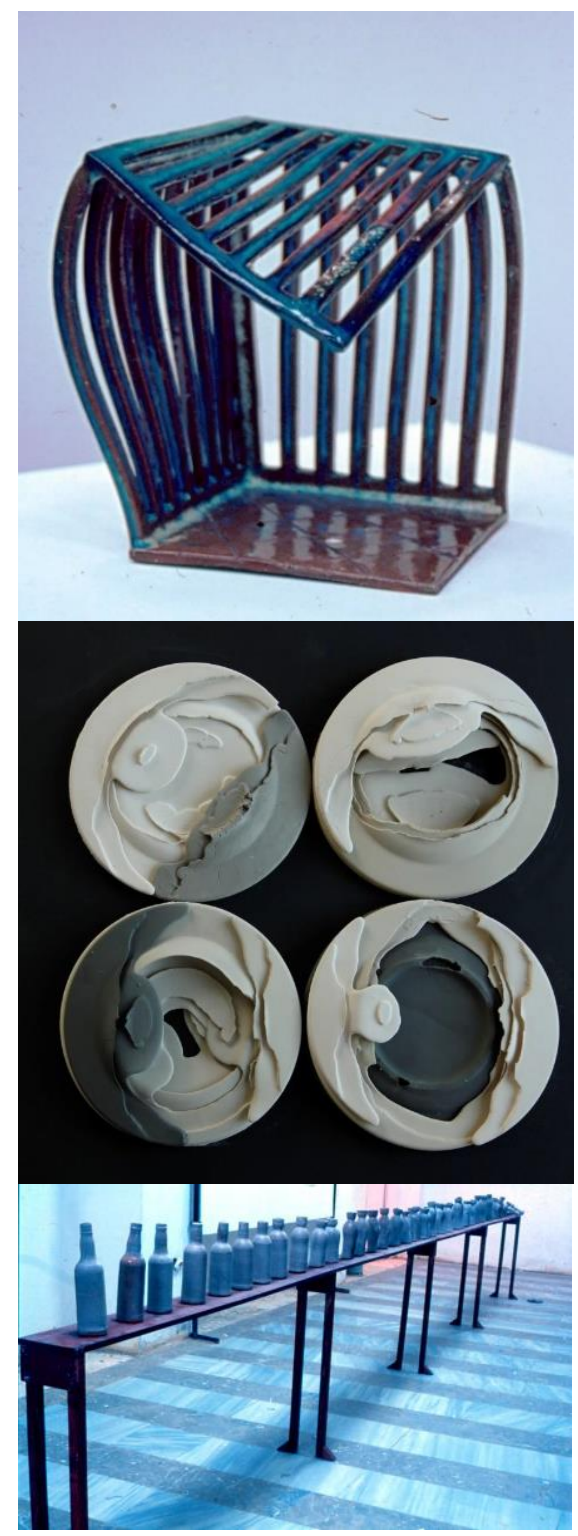

Picture 5.

One of the biggest privileges of the ceramics is its taking its last form by being fired at 900- $1400{ }^{\circ} \mathrm{C}$.

The seen form deformation event can only be thought by a ceramist; as the kiln is an important element of ceramic language.

Before entering into the oven, this work of art was an object in its square with every of its way!

(artist: Zeynep Mandıra, a student of mine from Marmara University Fine Arts Faculty)

\section{Picture 6.}

Here the plate form, with ceramic casting mud, into casting mold of gypsum is poured several times. The castings were made with specially as faulty and different colored mud. Then, the faulty and unfinished plate forms were too added on top of the other.

It is only a very unique fact that only the ceramic artists can think and practice it.

(artist: Aynur Karakaş)

Picture 7.

Realized in the direction of the above suggestions; the name of this settlement is: "The alcohol does not stand as it stand in the bottle"The bottles which are being deformed gradually and at last which sees the basement! This is a work of art that only a ceramist can think and realize. It seems that all of the elements like the potter's wheel, the wet of the clay and as a consequence its form's deformation gathered together in order to form the concept which is subject to word. Is it possible here to place another thing instead of ceramics? (artist: Hayali Dimiler, a student of mine from Marmara University Fine Arts Faculty) 

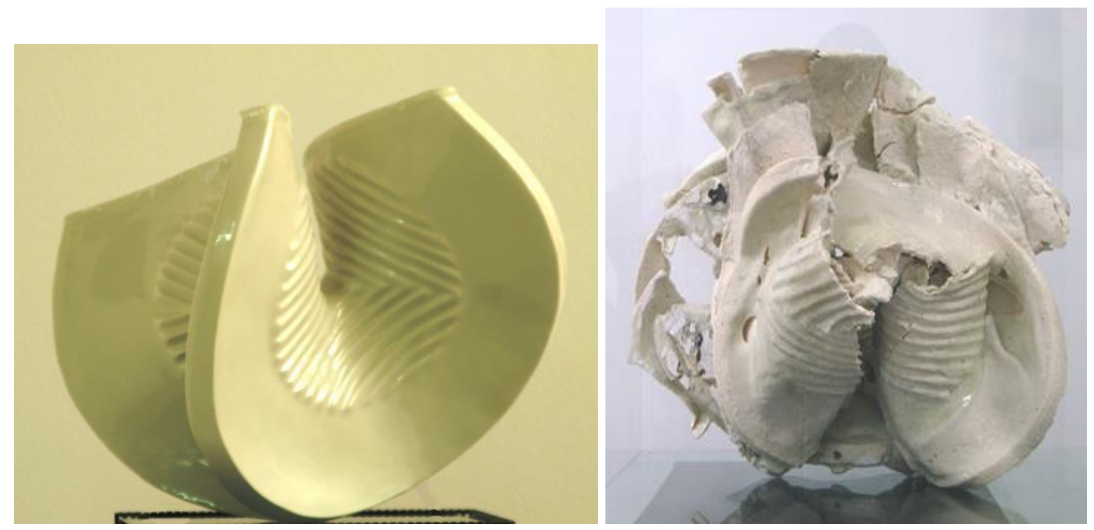

Picture 8-9

Above is the sculpture of which its casting has been made with the classic porcelain clay at right locked in a close embrace appearance of the sculpture after firing that of which is two of its casting in number have been made into the same pattern with paper porcelain clay and those of which firing have been made as it is positioned side by side in the oven...A gift of a different body and oven, to us; to ceramists, as an unforeseen gift, beforehand. But a very valuable element that can only be at the ceramists' palette after it is experienced once. (Its artist: Güngör Güner)
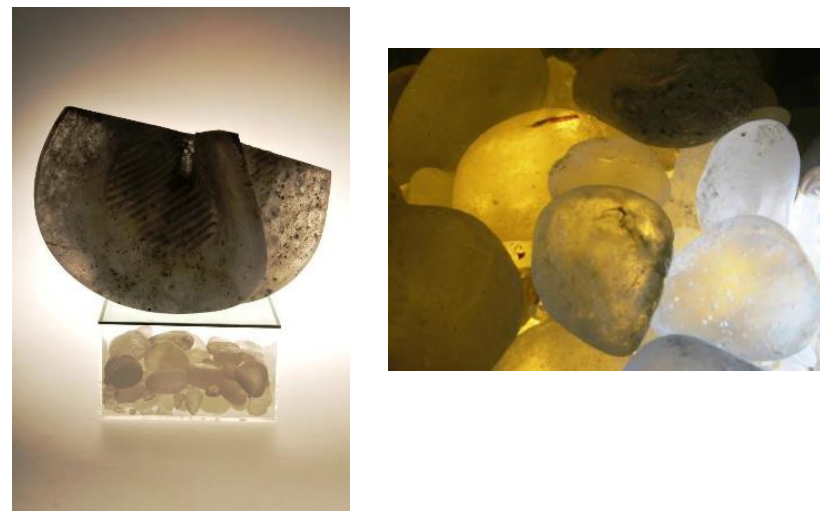

Picture:10-11

The same form as nr.8-9, Ø:45; $\mathrm{h}: 28 \mathrm{~cm}$ The glass sculpture you see on the right was made with the method of Páte de Verre.

The first construction of the statue was unsuccessful. I broke it and grinded it in a water ball-mill. So the glass pebbles you saw inside the stand were formed. By the way the glass fragments were rid of the waste and I have got the exclusively stones that only a ceramicist could make it. 

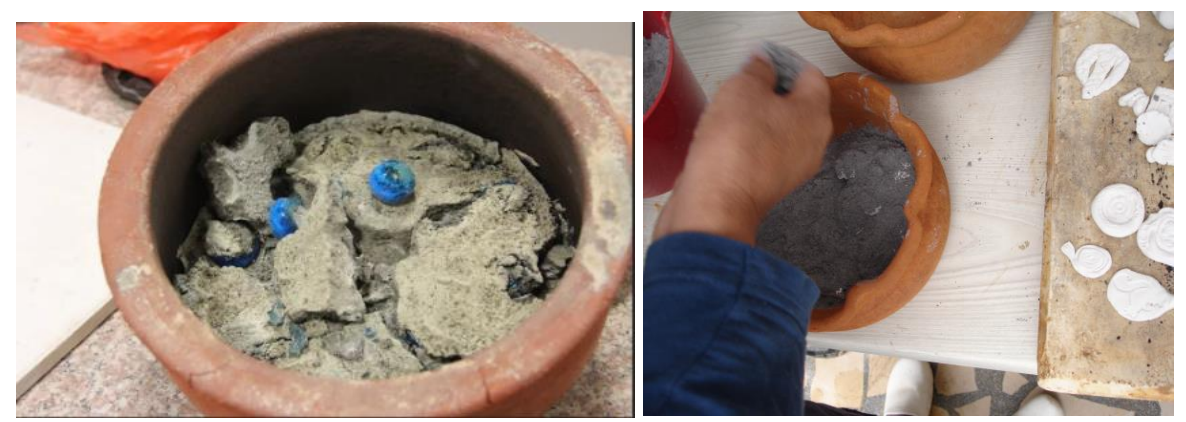

Picture12-13.

Mule beads made by sole silica body in Iran's City of GUM (sand); they are fired by being lined into a special mixture of ash and the products can be extracted from inside of mixture of ash as their every side are glossed and they are not sticking to any place after the firing. I first had the information about this technique in 1980 by the help of the article that Barbara Kleinman has published in the Keramik Magazine. Later on, I made several researches about different ashes and pigments which give color and published these researches. (Look at: 1992 The Book of Notifications of Turkish Ceramics Association: “Story of a Nile Blue", page: 619 - 621, publishing Number: 5)

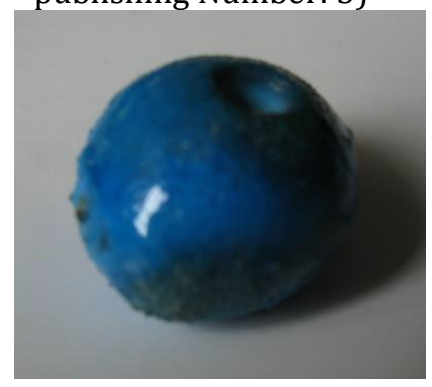

Picture 14. After firing and cleaning from ash mixture of the Mule Bead

\section{The story of my own installation.}

It wasn't directly my aim to make mule-beads if I made some research about the silica ceramics fired as embedded in an ash mixture. My main goal was: How can I make an art work out of, with this magic, traditional mule-beads technique of İran.

So, I will present the story of the concept blow. Which takes place in the content of a serial workout that has been going on since 1993 with the subject of "I am Displaying The Water" On line with the suggestion above. Besides which factor came together and what kind of event triggered this art work. 

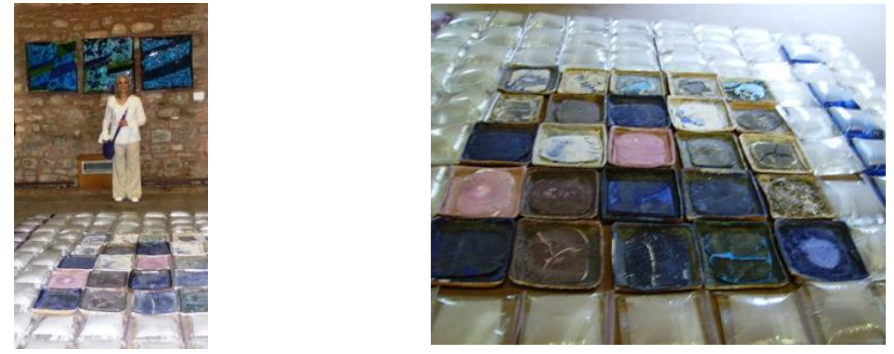

Picture 15-16.

Güngör Güner,2007 on

the wall.Paper-Clay

mirrors with silica-

slips and the water

installation on the

bottom

\section{AM DISPLAYING THE WATER}

Yes, since 1993 I am exhibiting water ( $\left.\mathrm{H}_{2} \mathrm{O}\right)$, without which life is impossible and of which the abundance can be as destructive as its shortage What is interesting is this miracle called water that is colorless, odorless, transparent liquid and can take the form of its container. It consists of two chemical elements, of which one helps burning and the other is flammable!

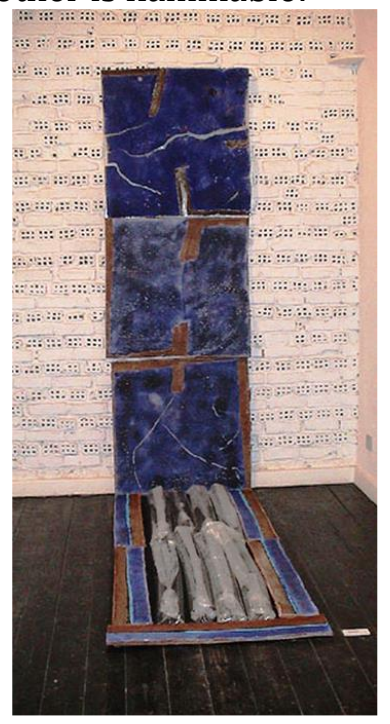

Picture 17.

Güngör Güner

From the series of "I am

displaying the water "

2004

(80x80x05

cm).3+(80x10x05 cm) Ash

glaze on red clay, $1150^{\circ} \mathrm{C}$

\section{Hydrogen}

Two units of tasteless and odorless hydrogen, of which the chemical symbol is "H", which is in gas form and has the smallest atomic weight $(1 \mathrm{gr})$ in the periodical table and has the least bonds $(1$ piece) and is used to obtain steel-welding requiring high heat when burned, go into reaction with one unit of oxygen and become water (H20). Being converted into water when reacting with oxygen, this innocent element " $\mathbf{H}$ " can be used to obtain $\mathbf{H}$ bomb, which has a very strong destructive effect, when its atomic nucleus is composed instead of decomposed. Moreover, hydrogen has another extraordinary feature as its melting point is- $259.8^{\circ} \mathrm{C}$ and boiling point is $-258.8^{\circ} \mathrm{C}$. 


\section{Oxygen}

Oxygen of which the chemical symbol is " 0 ", atomic weight is $16 \mathrm{gr}$, which has 2 bonds and is normally in gas form; forms $50 \%$ of the earth, $23 \%$ of the air we breathe and $27 \%$ of the water and finally the second element of water that enables us to breathe... Its melting point is $-218.7^{\circ} \mathrm{C}$ and boiling point is $-182.97^{\circ} \mathrm{C}$.

Combustion cannot take place without oxygen! Therefore, each oxidation is actually a combustion process. It takes place very slowly at normal heat. For example: Corrosion of iron, wearing of wood, even activities in our body caused by breathing and countless combustion events, of which the flames can be observed, at high levels of heat.

As a result of slow combustion (oxidation), metal oxides are generated and known ceramic products are produced as a result of different combination and processes of heat resistant metal oxides.

Belief and Water: When we examine the perspective in mythology and divine religions related to water; we see that they all agree with the same view: "WATER IS GOD". When it rains, they say "It's raining grace" in Anatolia... The lexical meaning of grace is God! The drive in all kinds of existence in mythology or divine religions is a divine energy!

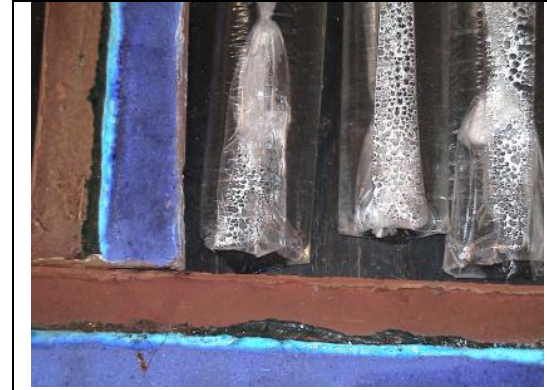

Picture 18

Detailed from picture 17

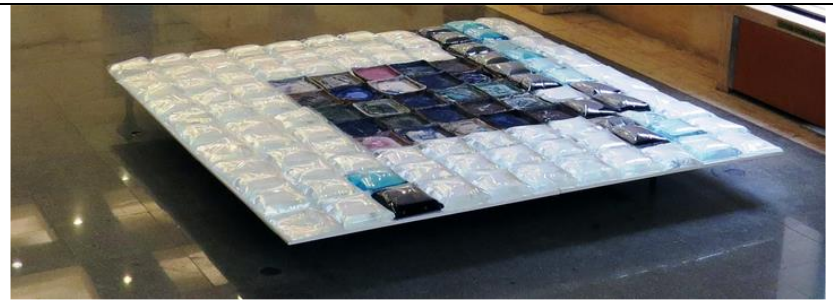

Picture 19.

Güngör Güner, Relationship Between Earth -Water and Transparency 1993, 330x290 cm, Embedded quartz ceramics in ash glaze represent the formation of earth; colored and colorless water in plastic bags express that sometimes earth can pollute water and sometimes water can pollute earth!"

\section{Why am I Displaying the Water?}

I was born in Omerli village in Beykoz-Istanbul but I spent my childhood in an old wooden house with a garden in Usküdar when the population of Istanbul was nearly one million. Water cut we used to experience every once in a while was a natural part of our lives. What a grief it was... Hamidiye Fountain was close to our house... Fifth floor of an apartment building, where I was going to live for twenty five years, in Maçka when Istanbul became a desert of apartment buildings with a population of twenty million. The only time we could have water there was midnight.

And the year 1993 was the driest year I had ever seen. It rained neither in summer nor in winter. The trees were bone-dry although it was spring. Then the rain came but it 
didn't fall on ground! The trees caught all the rain and burst into bud and bloomed the other day. Then it rained again and all rain was captured by the trees without letting it fall on the ground. Next day all of them came into leafs. Meanwhile, it became impossible to have water on the fifth floor and I started to carry buckets of water to the fifth floor only when the doorman a favor to fill my buckets... One day an American friend of mine forgot 1-2 pieces of quadrangular plastic bags that can automatically be closed in my house. As I was used to do so, I immediately filled the bags with water. Water bags lined up in the bathroom were looking really nice... During those days, I was preparing to open a ceramic exhibition in an art gallery that was converted from an old tradition Turkish Bath.

Suddenly I realized that somehow I could exhibit these bags as well.

I intended to give the viewers that message: "Water is now so rare that it can be exhibited in an art gallery" This was the first installation I made and it was totally a result of conditions, not an imitation !

The manifest of the installation was carrying on: "The need and invention of the Mankind to make pots from clay go back to the end of the Neolithic Age, which is 7000 years ago. Therefore, the relationship between ceramic and water goes back to those ages. However with this artwork, I wanted to achieve a new, free and individual aspect as regards this ceramic- water relationship and giving them a new dimension. Moreover, I wanted that the people may kindly take note some messages as well as I aimed to give them.

For example: I tried to draw attention to the fact that water has become so rare and valuable that it may be shown at least in the exhibition halls in these days. In spite of the unavoidable usage with simultaneous damnation of the unloved plastic bags, these latter nevertheless justify in the newest material "plastic" and the oldest material "ceramic" how they unite and marry for an art work and surprise us their joint.... 


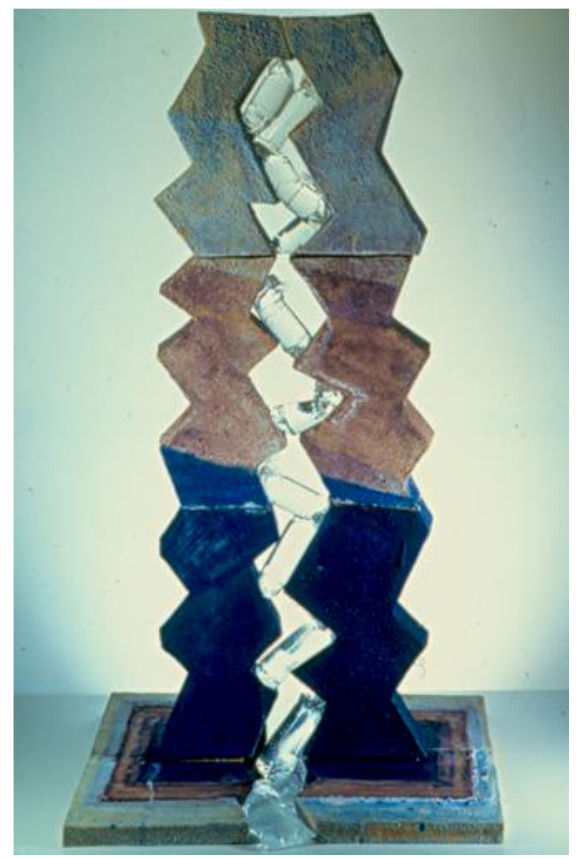

Picture Picture 20

Güngör Güner, I am Displaying the Water,1999 h:225 cm, w:60cm, d:25 cm Ash glaze on fireclay, $1150{ }^{\circ} \mathrm{C}$

Thus, I have been exhibiting water since 1993 I continue to work on the "I am Displaying the Water "concept. I keep on making objects to be filled water and realize my two or three-dimensional art works to exhibit water in a visible and touchable way when my muses visit me....

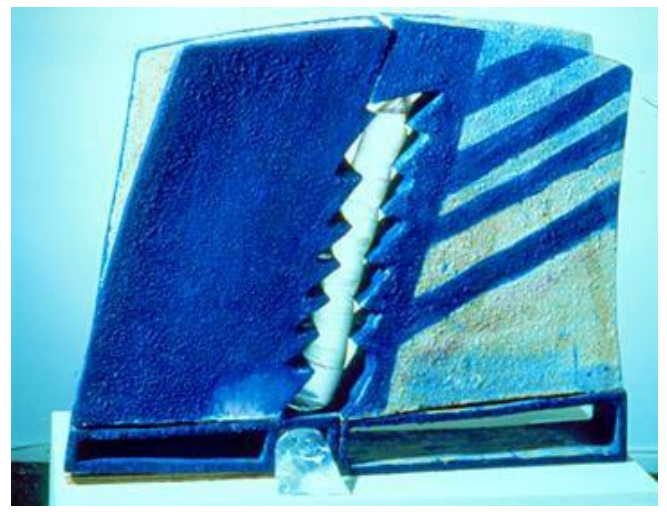

Picture 21. Güngör Güner, I am displaying the Water, 1999 h.70 cm, w:120 cm d:12 cm.ash glaze $1150{ }^{\circ} \mathrm{C}$ 


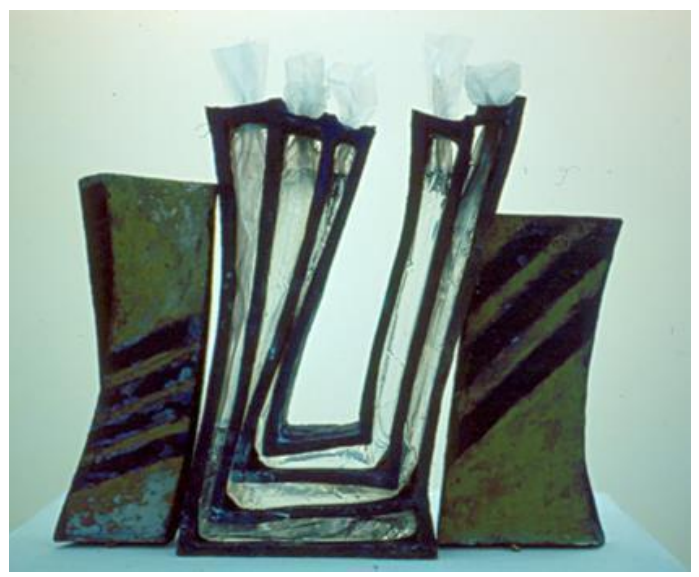

Picture 22.

Güngör Güner, I am displaying the water 1993 h.80 cm,w:70 cm,d:12cm Ash glaze on fireclay $1150{ }^{\circ} \mathrm{C}$

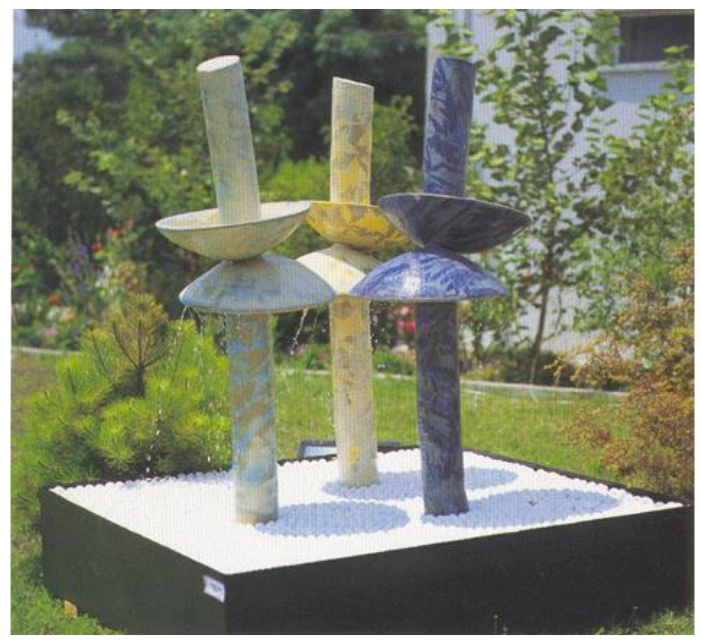

Picture 23.

Güngör Güner Kaskad, 2000 h.160 cm ,w:35 cm, Ø:12, Ulaksit glaze on Fire Clay $1150^{\circ} \mathrm{C}$ References

[1] METIN AND, Ottoman-Islam Mythology with Miniatures. AKBANK Publications (3)

[2] DTV Lexikon, Deutscher Taschenbuch Verlag (1),(2) 